\title{
What You Need to Know about Air Pollution: Its Importance and Effective Solutions
}

Air pollution is now one of the most pressing environmental concerns. While nine out of the ten most polluted cities in the world lie in India and Pakistan that leaves no room for complacency amongst other countries; partly because they too have their own issues and also because we live in a connected ecosystem.

\section{What Is Air Pollution?}

Air pollution is a complex topic as so many factors are responsible for the poor quality of our air. However, simply put, air pollution is any chemical, physical or biological change which causes the atmosphere to become dirty and thus risks not only our own potential for survival but also that of other animals and plants.

Air pollution can also be further divided into two distinct categories; visible and invisible. Both can lead to an alteration of the delicate balance of our atmosphere and cause problems to health on a local scale and also damage to the ecosystem globally in terms of depletion of the ozone layer leading to climate change.

Air pollution can arise in two main ways. First, pollutants can be released directly into the atmosphere and are known as primary pollutants. Second, primary pollutants can combine to form secondary pollutants and this can be seen in the formation of issues such as smog.

\section{What Causes Air Pollution?}

Fossil Fuels: A main cause of air pollution is the one you might expect, namely the sulphur released from the burning of fossil fuels, such as coal and petroleum. We rely on petrol, diesel and jet fuel to transport not only us but our goods around the world as we live in an increasingly globalised economy. In 2015 alone nearly 3.6 billion passengers, almost half the world's population, were transported by the world's airlines.

Vehicle Emissions: As our reliance on cars, trucks, shipping freighters and aeroplanes increases so do the levels of carbon monoxide and nitrogen oxides released into the atmosphere. $13 \%$ of global $\mathrm{CO} 2$ emissions, a major factor in global warming, come from transport.

Agriculture: We may not always immediately think of agricultural activities being connected to air pollution but methane and ammonia are both by-products of farming and are highly hazardous to our environment. This is compounded by the use of pesticides, insecticides and fertilizers, a heady cocktail of chemicals, some parts of which make it into the air.

Manufacturing: Heavy industry leads to the release of carbon monoxide, hydrocarbons and a soup of other chemicals, all of which can lead to a decline in air quality. Oil refineries also release hydrocarbons which pollute the atmosphere.

Deforestation: Deforestation is caused by clearing land for agriculture, manufacturing and ever growing urban areas. This lowers air quality because the fewer trees there are the less carbon dioxide they can absorb.

Mining: The result of mining on the health of workers and nearby residents has been clearly demonstrated over the years and in developing countries the quest to extract as many tons of natural resources as possible is having a devastating impact on the health of those working in the mines.

Indoor Pollution: What we use in our own homes is also leading to air pollution. Household cleaning products, paints and varnishes release chemicals into the air which contribute to poor air quality and many of us add to this chemical mix by smoking.

\section{What Damage Does Air Pollution Do?}

Air pollution damages our environment, and it also leads to a variety of health issues and even death.

Circulatory and Respiratory Issues: The particulates in the atmosphere have been linked to heart problems, respiratory issues and even cancer. Current estimates are that polluted air causes 5.5 million premature deaths per year.

Climate Change: The rise of levels of carbon dioxide, alongside other greenhouses gases, has led to 
global warming which has caused increasingly unpredictable weather systems and the melting of the ice caps.

Thinning of the Ozone Layer: As the levels of hydro chlorofluorocarbons and chlorofluorocarbons in the atmosphere rise this leads to a depletion of the ozone layer which protects the planet. As it does we are exposed to higher levels of ultraviolet light which can cause skin and eye problems.

Acid Rain: As sulphur and nitrogen oxides are released into the atmosphere they can combine with water droplets and fall as acid rain. The results can be devastating to fish, wildlife, trees and even the crops we rely on for our food production.

\section{What Can Be Done About Air Pollution?}

Air pollution needs to be tackled at a global level through legislation and international agreements which aim to reduce pollution levels, such as the Paris Agreement which was agreed in December 2015.

However, there are also steps we as individuals can take to lower our own environmental impact, particularly when it comes to air pollution.

Reduce Your Use of Private Vehicles: Where possible travel to your destination on foot, by bicycle, on public transport or car pool with others in your area. By lowering vehicle emissions you can reduce your carbon footprint.

Conserve Energy In the Home: Reduce your use of electricity by purchasing eco-friendly goods, keeping your thermostat turned down and insulating your property. Switch to sources of renewable energy where possible.

Recycle: Try to buy less from new and recycle household items as well as everything you are throwing out, even food scraps can go on a compost heap.

Reduce Food Miles: By purchasing more local food from farmers' markets and growing your own fresh produce you can drastically reduce the distance your food travels to reach your plate.

Improve Your Indoor Air Quality: As well as the steps above you can also improve the air quality in your own home by asking smokers to light up elsewhere; avoiding harsh cleaning agents; minimising your use of synthetic air fresheners; opening the windows regularly; and including plants in your interior design.

While it is sometimes easy to dismiss poor air quality as something which doesn't concern us, we only have to take a look at the statistics to understand the negative impact pollution is having on us and on our world. It is also important to remember that it is vital for us all to take action today if we don't want to leave a legacy it will be impossible for future generations to reverse.

(BIO: Joe is a writer from the UK, who creates articles on a range of subjects, including health and nutrition, sustainability and environmental issues. He believes living a healthy lifestyle will ensure a good platform for a happier life. This will help provide a better environment for us all, and help keep us more free of disease. Raising awareness on such issues is important for progression - education is key. joe@allgreenpr.com) - if required 